\title{
Monte Carlo Simulations as a Tool to Support Quantitative Value for Money Assessment of Public Private Partnership Project
}

\author{
Dinh Thi Thuy Hang ${ }^{1} \&$ Nguyen Thi Kim ${ }^{1}$ \\ ${ }^{1}$ Faculty of Banking and Finance, Hoa Sen University, Vietnam \\ Correspondence: Dinh Thi Thuy Hang, Faculty of Banking and Finance, Hoa Sen University, Vietnam.
}

Received: May 16, 2021

Accepted: June 16, 2021

Online Published: June 23, 2021

doi:10.5430/rwe.v12n3p97

URL: https://doi.org/10.5430/rwe.v12n3p97

\begin{abstract}
Value for money assessment is a crucial approach to compare the value of a project done by Public Private Partnership (PPP) with traditional government procurement. However, one of the most challenges in Value for money (VFM) assessment is uncertainty in inputs, which lead to imprecise output computation. To solve this issue, some practical studies suggest Monte Carlo Simulations (MCS) as a tool to support quantitative Value for money assessment to achieve reliable outcome estimation. Although many international researches focus on quantitative VFM analysis with the use of MCS, few Vietnamese studies conduct this issue. This research illustrates the application of MCS to support quantitative VFM assessment of PPP projects in Vietnam. A case study of a transport project in Vietnam is employed to demonstrate the model.
\end{abstract}

Keywords: Value for Money (VFM), Public Private Partnership (PPP), Monte Carlo Simulations (MCS)

\section{Introduction}

Public policy makers usually use Value for money to select which method between government procurement and Public Private Partnership (PPP) to fund a project. In particular, they estimate the cost of a project conducted by public-private partnership and by government procurement, and then they make comparisons of the value of each method. Conventionally, they utilize single estimation to calculate quantitative Value for money. However, Value for money assessment encompasses analysis of a candidate project by evaluating risks that affect a candidate project (Deepark et al., 2015). Inaccuracies in the calculation of risk factors can result in wrong decisions (Cruz \& Marques, 2013). Therefore, instead of employing a single point value, the VFM output may be a probability distribution to generate the uncertainty of the computation.

Some countries have succeeded in employing quantitative Value for money assessment with the combination of Monte Carlo Simulations to justify the selection of Public Private Partnership to fund transport infrastructure projects. Given their experience, Australian Government, Canada government, Korean government and among them have provided several guidelines on quantitative Value for money assessment. Besides the guidelines, several empirical studies have conducted quantitative Value for money assessment, such as the research by Tsukada (2015), Sarmanto (2010), Gil (2013) and among them. Many studies or guidelines on quantitative Value for money analysis with the use of Monte Carlo Simulations to select the best option to fund a specific project have been implemented outside Vietnam (especially developed countries) and very little has been covered in Vietnam. This research provides a guideline of application of Monte Carlo simulations in quantitative Value for money assessment of Public Private Partnership in Vietnam.

\section{Literature Review}

Quantitative Value for money assessment is defined as "a methodology that compares the Public Private Partnership bid with a hypothetical scenario called the Public-Sector Comparator (PSC)" (Morallos \& Amekudzi, 2008, p.115). Gvien the suggestion of the World Bank (2013), the quantitative Value for money analysis process comprises four phases (see Figure 1), namely (1) compute the project's costs if it is done by Public Private Partnership and the traditional delivery, (2) make adjustments to fair comparisons, (3) assess risk, (4) compute present value of Public-Sector Comparator and Public Private Partnership bid, and (5) compute Value for money. 


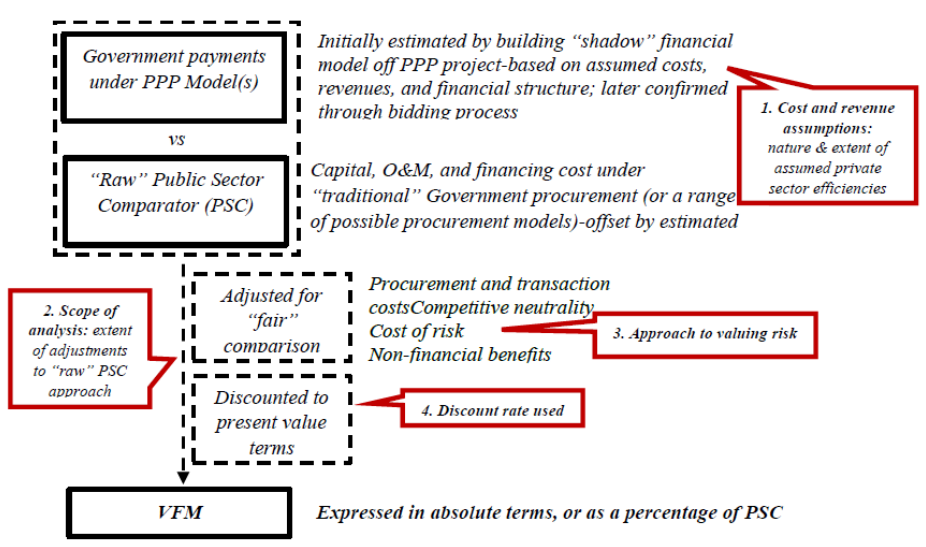

Figure 1. Overview of quantitative value for money assessment

Source: World Bank (2013)

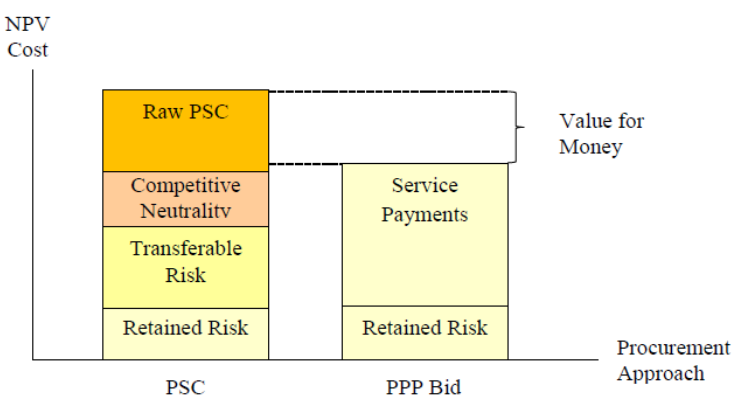

Figure 2. Comparison of PSC and PPP bid

Source: Marollas et al. (2009)

As shown in Figure 2, a project can create a Value for money if the net present value of the project done by the government (PSC-Public Sector Comparator) is larger than that under Public Private partnership. To specify, if the Value for money is larger than zero, the project is better to be implemented by Public Private Partnership. Meanwhile, if the VFM is smaller than zero, the project should be conducted by the government.

A Value for money analysis depends on a comparison of the values of the components of the Public Sector Comparator and the Public Private Partnership bid. The Public Private Partnership bid is computed by the private sector, while Public Sector Comparator is an assumed calculation of the expenditure, which is influenced by "the ambiguity and complexity problems" (Ismail et al., 2012). Some existing Value for money studies applied single point valuation to measure the Value for money outcome. However, valuation of a single point without considering the uncertainty of the input factors will only create one value that is not based on the possible risk of the outcome. Therefore, instead of focusing on a single point valuation, it is better to use the Monte Carlo Simulation (MCS) to simulate the variation of Value for money outcomes involving the uncertainty in the inputs (US Department of Transport, 2012; Partnerships British Columbia, 2009; Park, 2014). In this research, Monte Carlo Simulation is used to produce the distributions of the simulated Value for money output through probability distribution of input figures

\section{Value for Money Assessment Procedure Using Monte Carlo Simulations}

Monte Carlo Simulation is defined as a method employed to simulate a formula with a set of uncertainties in the input figures via random interactions that take stand on an assigned probability distribution (Glasserman, 2003). The process is iterated many times until the expected amount of results is achieved. Consequently, probability distribution of outcomes is produced, then this is used to analyze. The VFM assessment process of Monte Carlos simulation can be broken into Figure 3. 


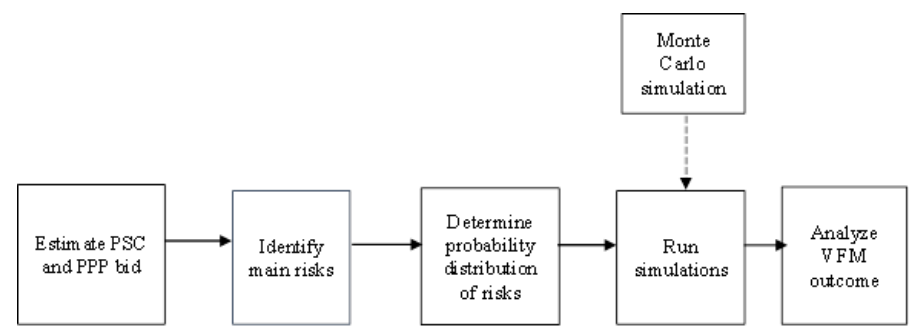

Figure 3. VFM assessment process by Monte Carlos simulations

Stage 1: Estimate Public Sector Comparator and Public Private Partnership bid

At this stage, based on available information of data from the feasibility study report of the projects and some assumptions, the value of Public Sector Comparator and Public Private Partnership bid are estimated.

Stage 2: Identify risk variables

We can identify risks based on the use of risks which are described in a sensitivity analysis (Tamošiūnienè and Petravičius, 2006) or drawn from literature reviews or interviews of experts.

Stage 3: Determine probability distribution of risks

As risks are identified, the best fit distribution of them is selected. Normally, historical data is used to define a range of value and probability distribution.

Stage 4: Run simulations

As assumptions are set, we run simulations. The values of risk are chosen randomly in accordance with the assigned probability distributions. Monte Carlo simulations are run to generate random numbers.

Stage 5: Analyze Value for money outcome

This is the final stage of the Value for money assessment process, in which analysis and interpretation of the results generated during the step of running simulations are done. In particular, the simulations run in stage 4 create frequency distribution for the Value for money. Then it is transformed into a cumulative probability distribution of Value for money. Based on this, we can estimate how much confidence level that Public Private Partnership is better than the traditional delivery route to conduct a project.

\section{Case Study}

This session illustrates a case study of Phu My Bridge which was initially planned to be done by PPP but when into the project's operation, it was reverted back to the public sector. This study assesses VFM of Phu My Bridge to determine which procurement is better to carry out. Monte Carlo simulation is used to support estimation of the confidence level that PPP offers higher value than traditional government procurement.

\subsection{Estimate PPP Bid and PSC}

In order to estimate the Public Private Partnership bid and Public Sector Comparator, the value of their items is taken from a feasibility studies report on the Phu My project and some assumptions. The main points of the studies are summarized as follows:

- The amount of investment capital for constructing this project is VND 1,806,523million, in which the total of investment capital funded by the concessionaire is VND 541.66 billion and amount of investment capital from borrowings is VND 1,264.86 billion.

- The interest rate is $10 \%$. According to the contract, the period of the debt repayment began in 2009 and lasts to 2034. In addition, the equity cost is $7.25 \%$. Therefore, the value of the Weighted Average Cost of Capital is $7.21 \%$, which is known as the real discount rate.

- Return on investment is $13.47 \%$.

- The term of concession is 29 years.

- Vehicles are classified into 5 groups: vehicles under 12 seats (group 1), vehicles from 12 seats to 30 seats (group 2), vehicles with 30 seats or more and medium trucks (group 3), heavy trucks (group 4) and special trucks (group 5). The traffic volume is annually predicted to be 920,000 vehicles (for group 1), 440,000 vehicles (for group 2), 
1,610,000 vehicles (for group 3), 830,000 vehicles (for group 4); and 210,000 vehicles (for group 5) in 2009. The amount of vehicles is expected to rise at a rate of $13 \%$ per year from 2010 to 2021, and unchange covering 2022 to the end of the concession.

- The charge rate was VND 10,000 for vehicles under group 1 and 2, VND 15,000 for vehicles under group 3, VND 20,000 for vehicles under group 4, and VND 30,000 for vehicles under group 5 during the period 2009-2011. The charge rate rose to VND 14,000 for group 1, VND 18,000 for group 2, VND 30,000 for group 3, VND 52,000 for group 4, and VND 75,000 for group 5 for the years between 2012 and 2016. The charge rate is estimated to be VND 15,000 for group 1, VND 26,000 for group 2, VND 35,000 for group 3, VND 65,000 for group 4, and VND 100,000 for group 5 for the period covering 2017 to 2034.

Table 1. Estimation of PPP bid and PSC

\begin{tabular}{ll}
\hline Items & Value (million VND) \\
\hline PSC & $1,581,210$ \\
\hline SBP & $2,913,106$ \\
\hline VFM & $-1,331,897$
\end{tabular}

Source: Computed by authors

\subsection{Identify Main Risks}

According to the research of Park (2014) and guidelines of US Department of Transport (2012) and Partnerships British Columbia (2009), uncertainty factors impacting the changes of Value for money are traffic volume risk and construction cost overrun risk. Accordingly, this research applies Monte Carlo Simulation to create the distributions of the Value for money output via probability distribution of traffic volume risk and construction cost overrun risk.

\subsection{Determine Probability Distribution of Risks}

Based on the data of BOT road projects operating between 2010 and 2015 in Vietnam, Chi Squared Goodness of Fit Test (at 0.05 significance level) reveals that traffic volume risk follows an exponential distribution, whose mean value is -0.36 with a standard deviation of 0.45 (see Figure 4). In addition, data of road projects that were completed between 2003 and 2015 in Vietnam are used to identify distribution risk of construction cost overrun. The statistical Fit Test using Chi-Squared at a 0.05 significance level implies that the construction cost overrun risk follows a log-logistic distribution (see Figure 5). The average value of the construction cost overrun risk is 0.14 and its standard deviation is 0.54 .

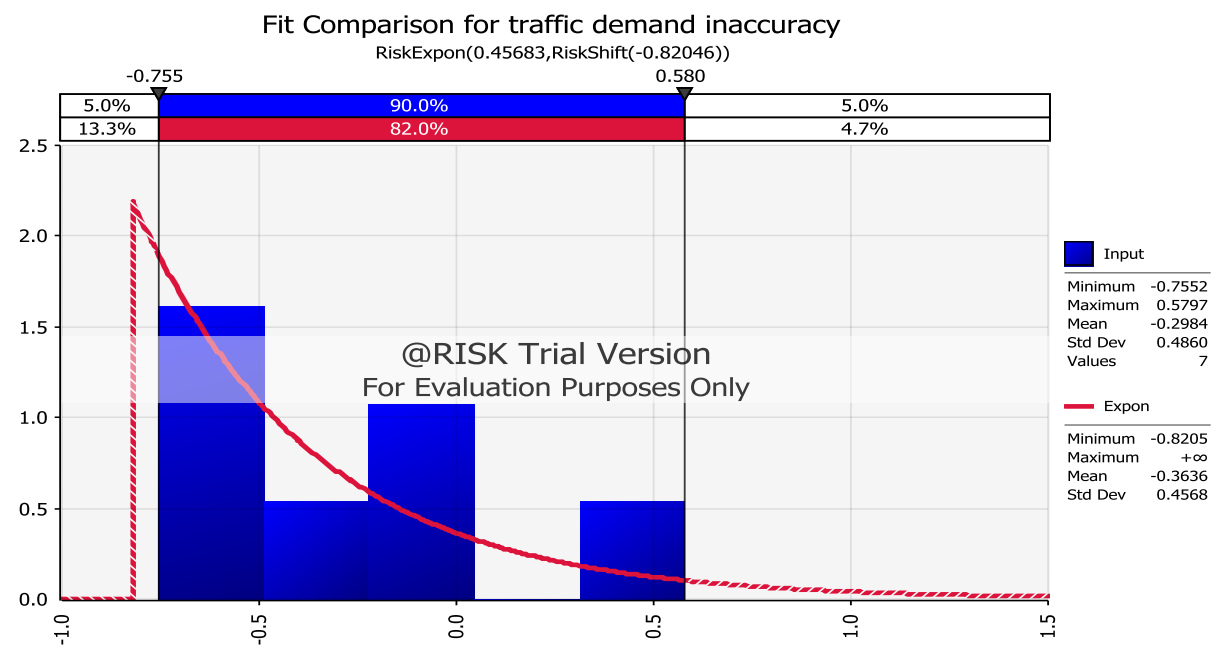

Figure 4. Probability density distribution for the traffic volume uncertainty 


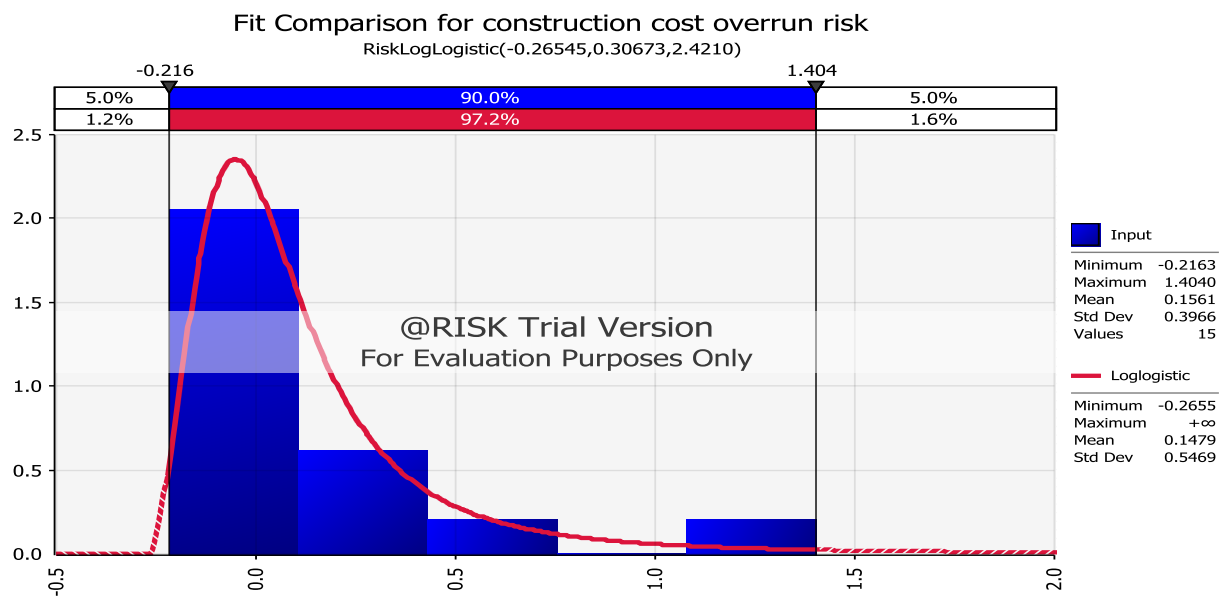

Figure 5. Probability density distribution for the construction cost overrun ratio

\subsection{Run Simulations}

A Monte Carlo Simulation with 10,000 repetitions was carried out to produce the values ranges of the Value for money output. The Palisade's @ Risk software (trial version 7.5) was applied to conduct the simulations.

\subsection{Analyze Quantitative Value for Money Outcome}

Figure 6 shows the probability distribution of Value for money while Figure 7 illustrates cumulative probability distribution of Value for money. As shown in Figure 7, the probability for positive Value for money is only 3.1\%. This means that conducting the project through Public private partnership is not as good as conventional procurement.

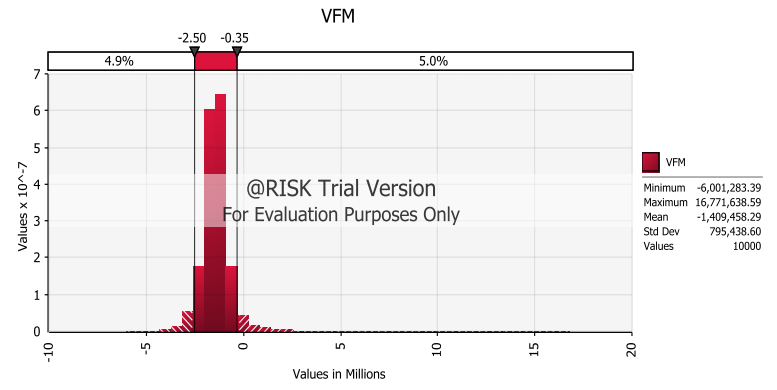

Figure 6. Distribution for the project's value for money

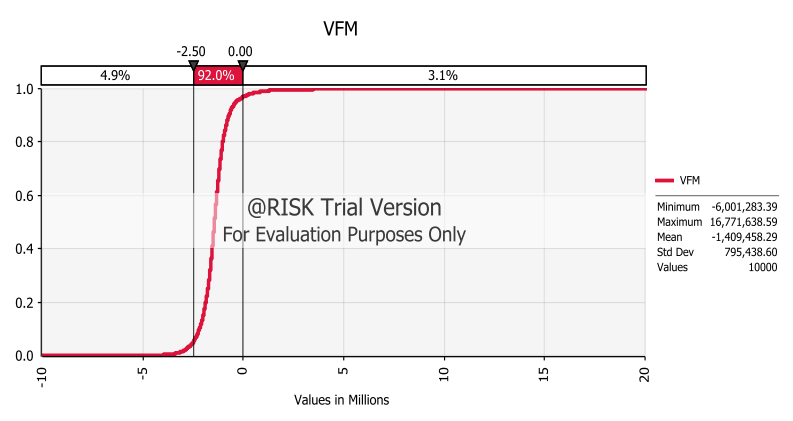

Figure 7. Cumulative probability of VFM 


\section{Conclusion}

Monte Carlo simulation is a significant tool in quantitative Value for money assessment. It provides a clear visibility of risks and Value for money outcome. To specify, the results show estimation of probability of Value for money outcome based on the simultaneous influence of uncertain inputs. In addition, it improves potentiality in Value for money assessment. It helps public policy makers estimate the probability that Public Private Partnership creates higher value than traditional procurement to finance a project. This research is expected to be a significant reference for public policy makers and researchers concerning making-decisions on selection of Public Private Partnership to develop transport infrastructure projects.

\section{References}

Australian Government. (2008). National Public Private Partnership guidelines - Volume 4: Public sector comparator guidance. Victoria: Commonwealth of Australia. Retrieved from https://www.infrastructure.gov.au/infrastructure/ngpd/files/Volume-4-PSC-Guidance-Dec-2008-FA.pdf

Deepak, S., Phoolendra, M., Hakob, A., \& Qingbin, C. (2015). Bayesian Network as a tool to ensure value for money from public private partnerships. Project Management Symposium.

Gil, B. (2010). A study on the optimal PPP model for transport: The Case of Road and Rail in South Korea. UK: PhD Dissertation, Faculty of Engineering and the Environment, University of Southampton. Retrieved from https://eprints.soton.ac.uk/361487/1/Ph.D\%2520thesis_B.GIL_final.pdf

Glasserman, P. (2003). Monte carlo methods in financial engineering. New York: Springer.

HM Treasury. (2008). Value for money and the valuation of public sector assessment. London: The Controller of Her Majesty's Stationery office. Retrieved from https://assets.publishing.service.gov.uk/government/uploads/system/uploads/attachment_data/file/191488/Green _book_supplementary_guidance_asset_valuation.pdf

Ismail, K., Takim, R., \& Nawawi, A. H. (2011). The evaluation criteria of Value for Money (VFM) of Public Private Partnership (PPP) bids. International Conference on Intelligent Building and Management (pp. 349-355). Singapore: IACSIT Press. Retrieved from https://www.academia.edu/26117904/The_evaluation_criteria_of_Value_for_Money_VFM_of_Public_Private_ Partnership_PPP_bids

Korea Development Institute. (2010). Detailed guideline for value for money test for BOT (PPP) projects. Korea: Public and Private Infrastructure Investment Management Center. Retrieved from https://www.kdi.re.kr/kdi_eng/kdicenter/detailed_guideline_for_vfm_test.pdf

Morallos, D., \& Amekudzi, A. (2008). A state of the practice of value for money analysis in comparing Public Private Partnership to traditional procurement. Public Works management Policy, 13(2), 114-125. https://doi.org/10.1177/1087724X08326176

Morallos, D., Amekudzi, A., Ross, C., \& Meyer, M. (2009). Value for Money Analysis in U.S. Transportation Public-Private Partnerships. Journal of the Transportation Research Board, 2115, 27-36. https://doi.org/10.3141/2115-04

Park, J. H. (2014). Transport PPP Decisions in Korea: Value for Money Assessment and Risk Quantification. UK: PhD Dissertation, Faculty of Engineering and Environment, University of Southampton. Retrieved from https://eprints.soton.ac.uk/366813/1/_userfiles.soton.ac.uk_Users_slb1_mydocuments_Final_thesis_Jihong_P ARK.pdf

Partnership British Columbia. (2009). Methodology for quantitative procurement options analysis: discussion draft. British Columbia: Partnership British Columbia. Retrieved from https://www.infrastructurebc.com/files-4/documents/DiscussionDraft-MethodologyforQuantitativeProcurement OptionsAnalysisAugust2009finalv2.pdf

Sarmanto, J. M. (2010). Do public-private partnerships create value for money for the public sector? The Portuguese experience. OECD Journal on Budgeting, 10(1), 93-119. https://doi.org/10.1787/budget-10-5km8xx3fgws5

Tamošiūnienè, R., \& Petravičius, T. (2006). The use of Monte Carlo technique to support investment decisions. Business: Theory and Practice, 7(2), 73-80. https://doi.org/10.3846/btp.2006.09 
Tsukada, S. (2015). Adoption of shadow bid pricing for enhanced application of "value for money" methodology to PPP programs. Public Works Management and Policy, 20(3), 248-263. https://doi.org/10.1177/1087724X14563720

US Department of Transport. (2012). Value for money assessment for public-private partnerships: a primer. USA: Department of Transport. Retrieved https://www.fhwa.dot.gov/ipd/pdfs/p3/p3_value_for_money_primer_122612.pdf

World Bank. (2013). Value-for-money analysis practices and challenges: how governments choose when to use ppp to deliver public infrastructure and services. Washington, DC: World Bank Group. Retrieved from https://www.icafrica.org/fileadmin/documents/Knowledge/World_Bank/VFM-PPPs-World_Bank-PPIAF.pdf

\section{Copyrights}

Copyright for this article is retained by the author(s), with first publication rights granted to the journal.

This is an open-access article distributed under the terms and conditions of the Creative Commons Attribution license (http://creativecommons.org/licenses/by/4.0/). 